\title{
Importance of Varicocele Treatment for Male Infertility in the Days of Assisted Reproductive Technology
}

\author{
Kulvinder Kochar Kaur ${ }^{1 *}$, Gautam Allahbadia ${ }^{2}$ and Mandeep Singh ${ }^{3}$ \\ ${ }^{1}$ Scientific Director, Centre For Human Reproduction, India \\ ${ }^{2}$ Reproductive Endocrinologist, Rotunda-A Centre for Human reproduction, India \\ ${ }^{3}$ Consultant Neurologist, Swami Satyanand Hospital, India
}

*Corresponding author: Kulvinder Kochar Kaur, Scientific Director, Centre For Human Reproduction, 721, GTB Nagar, Jalandhar 144001, Punjab, India

Submission: September 04, 2018; Published: September 12, 2018

\section{Introduction}

Varicoceles represents a dilation of veins within the pampiniform plexus, present in $15 \%$ of the general population. Varicocele is one of the most common etiologies of male factor infertility present in roughly $30-40 \%$ of infertile men presenting with primary infertility and up to $85 \%$ of those with secondary infertility [1]. It represents one of the simplest, most cost effective, and most effective avenues for the treatment of an infertile couple thus reproductive medicine providers should try to treat it.

Varicoceles as a cause of infertility had been recognized since late $19^{\text {th }}$ century, with the $1^{\text {st }}$ report described in 1929 [2]. Subsequently different reports have been published showing the benefits of repair, which included improved semen parameters and natural fertility. Data from recent studies showed benefits in addition in sperm DNA fragmentation, T production and even assisted reproductive technology (ART) outcomes. Once almost a century later, with ART having developed many folds, varicocele has got totally forgotten in view of it being a simple, effective and treatable part of infertility. couple

Right now, 2 challenges regarding varicocele in an infertile

\section{A. To identify it and}

B. Defining the role of repair in the era of ART.

Identifying it is straight forward. Initial screening evaluation along with semen analysis of the male partner and if it is abnormal need for referral to a male reproductive specialist is advocated [3]. Even though American society of reproductive medicine (ASRM) has widely recommended, besides others for varicocele examination to be a routine part of the infertility evaluation, only one fourth of male partners ever get evaluated [4].

Since the diagnosis of clinical varicocele just requires physical examination by the male reproductive specialist easily and counselling can be done by the Dr. regarding merits of the repair versus observation can be done for the given situation. Thus, obtaining an abnormal semen result might be the decisive factor for further proceeding with therapy.

Following the diagnosis, treatment should find a way in the modern mode of treatment by ART. Recently Samplaski et al. [5] retrospectively examined 400 men who had undergone varicocele repair either using embolization or a microsurgical approach and measured the total motile count (TMC) before and after repair and they categorized the results by the percentage of couples considered as candidates for invitro fertilization (IVF), intra uterine semination (IUI),or natural conception. The mean TMC for the whole cohort increased $>2.5$ fold following repair. The most significant gains were seen in men having the lowest baseline TMC, with almost a 7 fold rise in men who had severe baseline oligospermia. Biggest revelation was those who were initially needing IVF, theoretically, shifted to the group requiring IUI or natural conception following varicocele repair. Roughly $2 / 3^{\text {rd }}$ of candidates for IVF at baseline improved to IUI/natural conception counts. This highlights the importance of treating varicocele, within the framework of ART.

Though Samplaski et al. [5] study was helpful in counselling couples, it did not provide real world ART decisions that were made by their physicians or the patients. It was calculated that the TMC of 9million needed for natural conception by taking the lower limit of normal fertility cutoffs from the WHO 2010 manual definition for each parameter of volume, concentration, and motility. Though TMC is the most clinically useful parameter of a semen analysis, the WHO 2010 manual did not find a lower limit of normal for TMC, and possibly it could be higher than 9 million, that was calculated by just combining all of the lower limits of its component parameters that were calculated independently.

Hence Samplaski et al. [5] results especially the men who managed to get their wives pregnant naturally with $>9$ million TMC after varicocele repair should be considered with this thing in mind. Limitations of this study is the lack of important outcomes namely 
pregnancy and live birth. Even though limitations are there this study represents a big multicenter cohort of infertile men having had undergone varicocele repair, is well designed for giving a counseling framework regarding value of varicocele repair vis a vis going for immediate ART.

Kirby et al. [6] published a meta-analysis involving $>1000$ patients regarding the importance of evaluation of the male partner along with treatment of varicocele on pregnancy and live birth if present for getting better pregnancy and live birth, for both oligospermic and azoospermia men undergoing repair before ART [5]. On comparing male partner having varicocele that was never repaired, with those couples where the male had repair of the varicocele, it was found that on varicocele repair prior to ART cycles there was 1.7 times greater chances of pregnancy and live birth.

This meta-analysis highlights the importance of examining the male partner along with treating the varicocele if present for improving pregnancy and live birth in this era of ART. Samplaski et al. [5] study gives further insight regarding how varicocele treatment can be coordinated within the complex framework of ART [6]. Though known earlier that varicocele treatment might improve semen quality and natural conception, this study guides that patient can shift from needing an IVF to a simple IUI, that is less invasive method or even need no treatment. Thus, simply treating varicocele might result in less invasive method, less expensive method or even natural pregnancy..

\section{References}

1. Clarke BG (1966) Incidence of varicocele in normal men and among men of different ages. JAMA 198(10): 1121-1122.

2. Macomber D, Sanders MB (1929) The spermatozoa count: its value in the diagnosis, prognosis, and treatment of infertility. Engl J Med 200: 981-984.

3. Practice committee of the American society for reproductive medicine (2015) Diagnostic evaluation of the infertile male: As committee opinion. Fertil Steril 103(3): 18-25.

4. Eisenberg ML, Lathi RB, Baker VL, Westphal LM, Milki AA, et al. (2013) Frequency of the male infertility evaluation: data from the national survey of family growth. J Urol 189(3): 1030-1034.

5. Samplaski MK, Lo KC, Grober ED, Zini A, Jarvi KA (2017) Varicocelectomy to upgrade semen quality to allow couples to use less invasive forms of assisted reproductive technology. Fertil Steril 108(4): 609-612.

6. Kirby EW, Wiener LE, Rajanahally S, Crowell K, Coward RM (2016) Undergoing varicocele repair before assisted reproduction improves pregnancy rate and live birth rate in azoospermia and oligospermic men with a varicocele: a systematic review and meta-analysis. Fertil Steril 106(6): 1338-1343.
Creative Commons Attribution 4.0 International License

For possible submissions Click Here

\section{Submit Article}

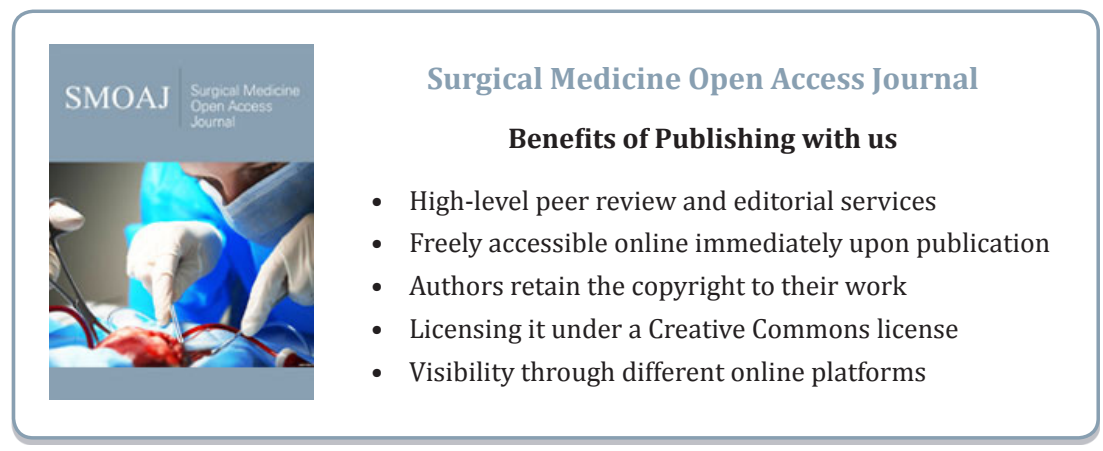

